\title{
An unusual toxicity with beta blocker and calcium channel blocker
}

\author{
Vijay Anand, Shalini Nair
}

The increasing use of beta and calcium channel blockers for management of cardiac
comorbidities has led to more frequent complications in the postoperative period.
Anesthetic interaction with these drugs can lead to delayed manifestations of features of
toxicity, even when administered in therapeutic doses. We report a case with an uneventful
intraoperative period but profound bradycardia and hypotension postoperatively, only
relieved with high-dose insulin therapy.
Keywords: Anesthetic interaction, beta blocker and calcium channel blocker toxicity,
hypoperfusion

\section{Introduction}

Beta blockers (BB) and calcium channel blockers (CCB) are the main group of cardiac drugs in use for several years. Unfortunately, they also remain common causes of cardiovascular collapse following accidental or intentional overdose. Toxicity is associated with significant mortality.$^{[1]}$ Toxicity with a regular dosage of these two drugs is not reported. We encountered a rare event of toxicity with $\mathrm{BB}$ and $\mathrm{CCB}$ in a patient who was electively posted for interbody fusion between $4^{\text {th }}$ and $5^{\text {th }}$ lumbar vertebrae (L4-L5).

\section{Case Report}

A 72-year-old gentleman weighing $68 \mathrm{~kg}$ and $160 \mathrm{~cm}$ tall and hypertensive on treatment for past 10 years with metoprolol-XL-50 mg and amlodipine $5 \mathrm{mg}$ was operated for anterolisthesis of disc at L4-L5 level with canal stenosis. He had previously undergone an uneventful surgery for right rotator cuff repair under general anesthesia 6 years ago. Present

From:

Department of Neurological Sciences, Christian Medical College, Vellore,

Tamil Nadu, India

\section{Correspondence:}

Dr. Shalini Nair, Department of Neurological Sciences,

Christian Medical College, Vellore, Tamil Nadu, India.

E-mail: drshalininair@cmcvellore.ac.in

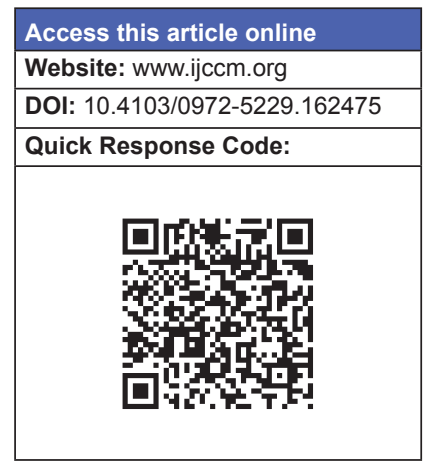

preanesthetic check-up was normal with heart rate $(\mathrm{HR})$ of $62 / \mathrm{min}$, blood pressure (BP) of $110 / 74 \mathrm{mmHg}$, normal electrocardiogram (ECG), and heart sounds on auscultation. His effort tolerance was only limited by pain in lower limbs. On the day of surgery, he received his regular antihypertensives. The preoperative cardiac assessment on the table was uneventful. Preinduction vitals were stable with $\mathrm{HR}$ of $58 / \mathrm{min}$ and BP of $122 / 78$. Premedication included glycopyrrolate $0.2 \mathrm{mg}$, fentanyl $100 \mu \mathrm{g}$, and ondansetron $8 \mathrm{mg}$. Anesthesia was induced with propofol $2 \mathrm{mg} / \mathrm{kg}$ intravenous (IV) and after confirming ventilation, vecuronium $0.1 \mathrm{mg} / \mathrm{kg}$ was given IV. Anesthesia was maintained with oxygen in nitrous oxide, supplemented with isoflurane, vecuronium and propofol infusion, and morphine. The blood loss was approximately $100 \mathrm{ml}$ and $1.5 \mathrm{~L}$ crystalloid was infused. Intraoperative period of $4 \mathrm{~h}$ in the prone position was uneventful except for a drop in BP at induction to $80 / 54 \mathrm{mmHg}$, which was managed with a bolus of $250 \mathrm{ml}$

This is an open access article distributed under the terms of the Creative Commons Attribution-NonCommercial-ShareAlike 3.0 License, which allows others to remix, tweak, and build upon the work non-commercially, as long as the author is credited and the new creations are licensed under the identical terms.

For reprints contact: reprints@medknow.com

How to cite this article: Anand V, Nair S. An unusual toxicity with beta blocker and calcium channel blocker. Indian J Crit Care Med 2015;19:496-8. 
crystalloid. He was extubated and vitals in the recovery room before shifting to Intensive Care Unit (ICU) were stable for HR of $64 / \mathrm{min}$ and $\mathrm{BP}$ of $108 / 54 \mathrm{mmHg}$.

An hour after receiving the patient in ICU, his BP dropped to $82 / 48 \mathrm{mmHg}$ with no change in HR or consciousness. Fluid boluses of $250 \mathrm{ml}$ ringer lactate in two aliquots were administered without benefit. ECG was normal with a sinus rhythm and nonspecific $t$ wave inversion in lead III. Arterial blood gas (ABG) on room air showed normal oxygenation with metabolic acidosis with elevated strong ion difference $(\mathrm{pH}-7.268$, $\mathrm{PaO}_{2}-112, \mathrm{PaCO}_{2}-40$, bicarbonate - 19.3 with BE - 5.6, and lactate - 1.9). Ultrasonography (USG) revealed completely collapsed inferior vena cava (IVC) which was treated with $2 \mathrm{~L}$ of crystalloid administered cautiously over $1 \mathrm{~h}$ without any significant improvement. The patient remained conscious and could move his lower limbs well ruling out any spinal shock. Vasoactive drugs (adrenaline, dopamine, and noradrenaline) were serially added and escalated to maximum $(20 \mathrm{mcg} / \mathrm{min})$ without any remarkable change in BP. The HR increased from 60 to 100/min. Gradually he began manifesting signs of hypoperfusion in multiple organs. His urine output reduced, and he developed hypothermia. Cardiac evaluation by a senior cardiologist with bedside $\mathrm{ECHO}$ and enzymes ruled out any cardiac pathology. Serial ABGs revealed worsening lactic acidosis and deteriorating oxygenation though mentation remained intact. After administration of $6 \mathrm{~L}$ of crystalloids, bedside USG revealed an adequately filled IVC without any signs of fluid overload in the lungs. Having ruled out cardiac pathology and hypovolemia as the cause of hypotension with worsening organ perfusion the possibility of $B B$ and CCB toxicity was considered. As glucagon was not available in the institution, we started an infusion of insulin in dextrose at $0.15 \mathrm{U} / \mathrm{kg} / \mathrm{h}(25 \%$ dextrose with 15 units of insulin at $60 \mathrm{ml} / \mathrm{h}$ ) (glucose-insulin-potassium therapy) along with calcium infusion at $0.5 \mathrm{~g} / \mathrm{h}$ and potassium at $30 \mathrm{mEq}$ over $3 \mathrm{~h}$.

Glucose and potassium values were monitored every hour, and the infusion was adjusted accordingly. Within an hour of treatment with this regime BP improved to $100 / 60 \mathrm{mmHg}$. The inotropes could be tapered and stopped within $2 \mathrm{~h}$, urine output improved and euthermia was attained.

\section{Discussion}

The combination of CCB and BB is increasingly used in the management of hypertension. Anesthesia can cause myocardial depression in patients on $\mathrm{BB}^{[2]}$ and silent myocardial ischemia in those on $\mathrm{CCB} \cdot{ }^{[3]}$ However, the effect of anesthesia on patients receiving combination of $\mathrm{CCB}$ and $\mathrm{BB}$ is unique and was studied by Samad et al., who found that hypotension (systolic $\mathrm{BP}<90 \mathrm{mmHg}$ ) and bradycardia (HR $<50 / \mathrm{min}$ ) were more common in CCB and BB group (55\%) than in BB group (15\%) alone. ${ }^{[4]}$ These episodes were transient and recovered on treatment with ephedrine. Negative inotropic effect of the combination in the presence of impaired left ventricular function has been suggested the cause for profound hypotension. ${ }^{[5]}$

The pathophysiology of toxicity arising from the two groups of drugs revolves around calcium signaling and cardiac myocytes switching from carbohydrates to fatty acids as preferred substrate for energy causing hyperglycemia and acidemia. ${ }^{[6,7]}$

The shock resulting from $\mathrm{BB}$ and $\mathrm{CCB}$ toxicity can be very resistant despite the use of all available catecholamines for resuscitation. ${ }^{[1]}$ Predictably our patient too did not show any improvement in BP despite the maximum doses of adrenaline, noradrenaline, and dopamine.

Traditionally BB toxicity is treated with glucagon and CCB with calcium gluconate infusion. ${ }^{[8]}$

Calcium salts have been recommended as initial therapy as positive inotropy may be beneficial, but they have varied results in improving hemodynamics. ${ }^{[9]}$ Engebretsen et al. ${ }^{[10]}$ in the review on role of high dose insulin (HDI) in treatment of BB and CCB toxicity concluded that it was a promising treatment and with minimal adverse effect profile and ease of availability supported its use. The benefits are attributed to the promotion of carbohydrate metabolism rather than direct effects on the calcium channel. The insulin doses used have varied widely ranging from 0.015 to $22 \mathrm{U} / \mathrm{kg} / \mathrm{h}$. Most of the patients receive between 0.5 and $2 \mathrm{U} / \mathrm{kg} / \mathrm{h} \cdot{ }^{[10]}$

The recovery of shock should be monitored with improvement in organ perfusion rather than chasing traditional hemodynamic parameters. Biochemical parameters and lactate concentration may also be useful tools. $^{[10]}$

This case highlights the possibility of $\mathrm{BB}$ and $\mathrm{CCB}$ combination and anaesthetic interaction that can lead to prolonged hypotension that has not been reported earlier. Timely consideration of this possibility and early initiation of HDI helped us avert severe organ damage. 
Inability to measure the serum drug level remains a drawback though the administered doses were in the therapeutic range.

\section{Conclusion}

Profound and refractory hypotension can be encountered in hypertensive patients on chronic BB and CCB therapy in the absence of toxic levels. Anesthesia in patients receiving these combinations can lead to not only transient intraoperative changes but prolonged hypotension and hypoperfusion that can lead to organ dysfunction. HDI can be a good intervention to revert the effects of toxicity.

\section{Financial support and sponsorship}

Nil.

\section{Conflicts of interest}

There are no conflicts of interest.

\section{References}

1. Kerns W $2^{\text {nd }}$. Management of beta-adrenergic blocker and calcium channel antagonist toxicity. Emerg Med Clin North Am 2007;25:309-31.

2. Slogoff S, Keats AS, Hibbs CW, Edmonds CH, Bragg DA. Failure of general anesthesia to potentiate propranolol activity. Anesthesiology $1977 ; 47: 504-8$.

3. Sear JW, Foex P, Howell SJ. Effect of chronic intercurrent medication with beta-adrenoceptor blockade or calcium channel entry blockade on postoperative silent myocardial ischaemia. Br J Anaesth 2000;84:311-5.

4. Samad K, Khan F, Azam I. Hemodynamic effects of anesthetic induction in patients treated with beta and calcium channel blockers. Middle East J Anaesthesiol 2008;19:1111-28.

5. Geddes JS. Calcium antagonists and beta blockade - A useful combination. Postgrad Med J 1983;59 Suppl 2:62-9.

6. Katz AM. Selectivity and toxicity of antiarrhythmic drugs: Molecular interactions with ion channels. Am J Med 1998;104:179-95.

7. Kline JA, Raymond RM, Schroeder JD, Watts JA. The diabetogenic effects of acute verapamil poisoning. Toxicol Appl Pharmacol 1997;145:357-62.

8. Shepherd G. Treatment of poisoning caused by beta-adrenergic and calcium-channel blockers. Am J Health Syst Pharm 2006;63:1828-35.

9. Tai YT, Lo CW, Chow WH, Cheng CH. Sucessful resuscitation and survival following massive overdose of metoprolol. Br J Clin Pract $1990 ; 44: 746-7$

10. Engebretsen KM, Kaczmarek KM, Morgan J, Holger JS. High-dose insulin therapy in beta-blocker and calcium channel-blocker poisoning. Clin Toxicol (Phila) 2011;49:277-83. 